\title{
Extinguishment of Rack Storage Fires of Corrugated Cartons Using Water
}

\author{
JAMES L. LEE \\ Factory Mutual Research Corporation \\ 1151 Boston-Providence Turnpike \\ Norwood, Massachusetts 02062, USA
}

AB STRACT

A series of large-scale fire tests were conducted on the extinguishment of corrugated cartons stored on metal racks. Three different storage heights $(3.0 \mathrm{~m}, 4.5 \mathrm{~m}$, and $6.0 \mathrm{~m})$ were investigated. A specially designed water applicator, supported at a close distance from the top of the test array, was used to deliver a uniform water application density directly onto the array. The applicator could be actuated at any stage of the fire development process to simulate sprinkler response under different fire scenarios. Products of combustion from the fire were collected by a large-capacity calorimeter for the determination of heat release rate for the entire test duration. The effects of water application rate, fire size at the time of water application, and storage height were examined. A single empirical correlation of the extinguishment data was established between the fuel consumed during extinguishment normalized by the fire consumable mass left at the time of water application, $\mathrm{M}_{\mathrm{ext}} / \mathrm{M}_{\mathrm{o}}$, and the water application rate normalized by the mass burning rate at water application, $\dot{M}_{w} / \dot{M}_{b}, w^{*}$ A power law relationship exists between $\mathrm{M}_{\text {ext }} / \mathrm{M}_{\mathrm{O}}$, and $\dot{\mathrm{M}}_{\mathrm{w}} / \dot{\mathrm{M}}_{\mathrm{b}, \mathrm{w}}$ with the power being -1.55 . The same kind of correlation was also obtained in a laboratory-scale extinguishment study on wood cribs and wood pallets of different heights. Based on the correlation, a critical water application rate (per unit exposed surface area) for rack storage array of corrugated cartons was determined to be $3.0 \mathrm{~g} / \mathrm{m}^{2} \mathrm{~s}$ which is very close to the values reported for wood arranged in other geometries such as crib, slab, and pallet.

\section{INTRODUCTION}

In the industrial fire loss history for the past decade, warehouse fires have been reported to be among the most costly. These fires present a severe challenge to existing sprinkler protection systems because of the configuration of the storage systems in the warehouses as well as the fire hazard potential of the new generation of storage materials. A popular approach in warehouse storage today is to store palletized goods on metal racks; this arrangement presents an ideal setup for accelerated flame spread among the storage goods upon ignition. Traditionally, the protection needs for this type of storage system were determined through full-scale fire tests; however, 
such tests are usually very costly and the data collected are primarily applicable to the particular test conditions chosen. In order to reduce the cost of fire testing and have data useful for a wider range of test conditions, a basic understanding of the suppressive action of water on these rack storage fires is essential.

In the past 20 years, a number of studies were conducted on the extinguishment of three-dimensional fuel structures using water alone ${ }^{1-6}$. The fuel examined was wood and the structures used were in the form of a crib or stack of pallets. Some interesting results were obtained in terms of a critical water application rate and the power law relationship between the fuel consumption during extinguishment and the water application rate. This study was intended to compare the results of this work with those from the laboratoryscale studies, particularly those by Kung and $\mathrm{Hi} 11^{3}$, to advance our understanding of the extinguishment behavior of large-scale rack storage fires of corrugated cartons such as encountered in actual warehouses.

\section{EXPERIMENT}

A series of 32 rack storage fire extinguishment tests were conducted at the Factory Mutual Test Center in West Glocester, Rhode Island. The fuel selected for the study was double triwall corrugated cartons with metal liners inside. Each carton measured $107 \mathrm{~cm} \times 107 \mathrm{~cm}$ x $105 \mathrm{~cm}$ externally and weighed $38 \mathrm{~kg}$ (excluding the weight of the metal liner). A picture of the carton is show in Figure 1. Each carton was placed on a wood pallet and stored on a double-row metal rack which allowed a two-pallet-load wide by two-pallet-load deep storage. Two-, three-, and four-tier high arrays were tested which had overa11 storage heights of $3.0 \mathrm{~m}, 4.5 \mathrm{~m}$, and $6.0 \mathrm{~m}$, respectively. Within each test array, flue spaces were maintained of $0.15 \mathrm{~m}$ between the vertical surfaces of the pallet loads, and of $0.33 \mathrm{~m}$ between the bottom of the pallets and the top of the commodity. A schematic showing the $4.5-\mathrm{m}$ high array is presented in Figure 2.

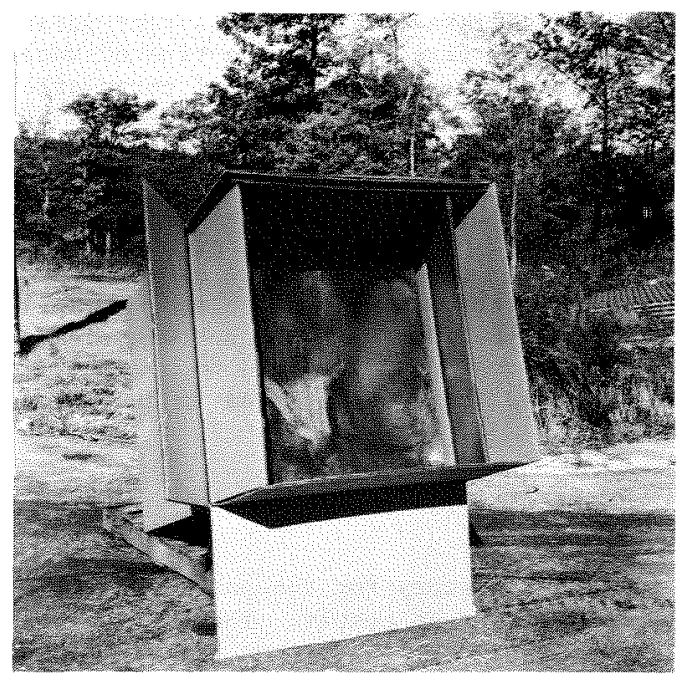

FIGURE 1。 Metal-1ined double triwall carton 
The entire test array was erected on a $3,600^{-\mathrm{kg}}$ load platform which continuously monitored the weight loss of the fuel during the test. A specially designed water applicator (see Figure 3), consisting of eight

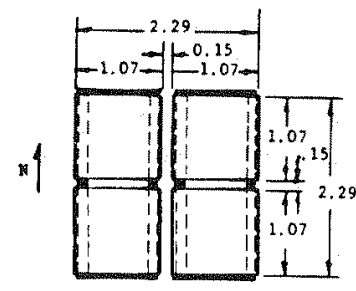

TOP VIEW
NOTE: ALL UNITS IN METERS

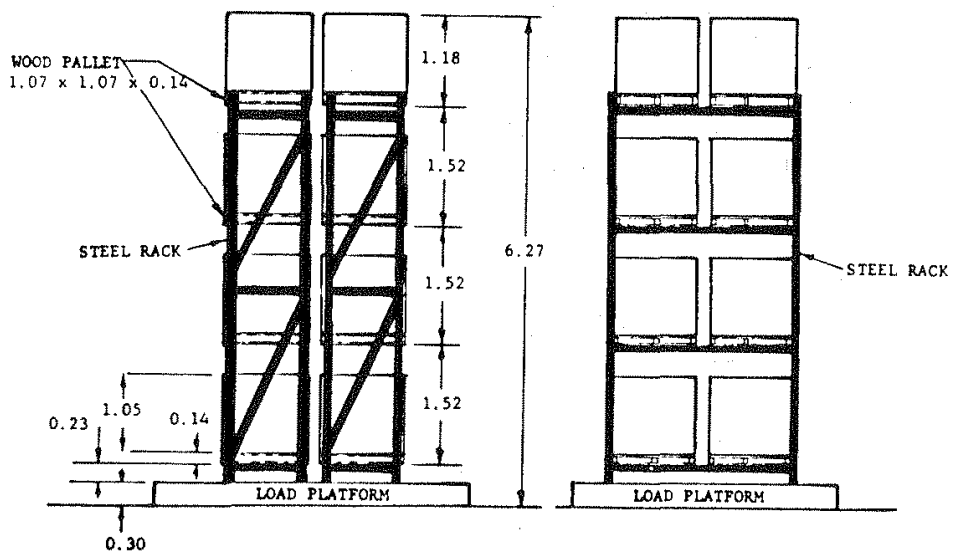

FIGURE 2. Four-tier high rack storage array.
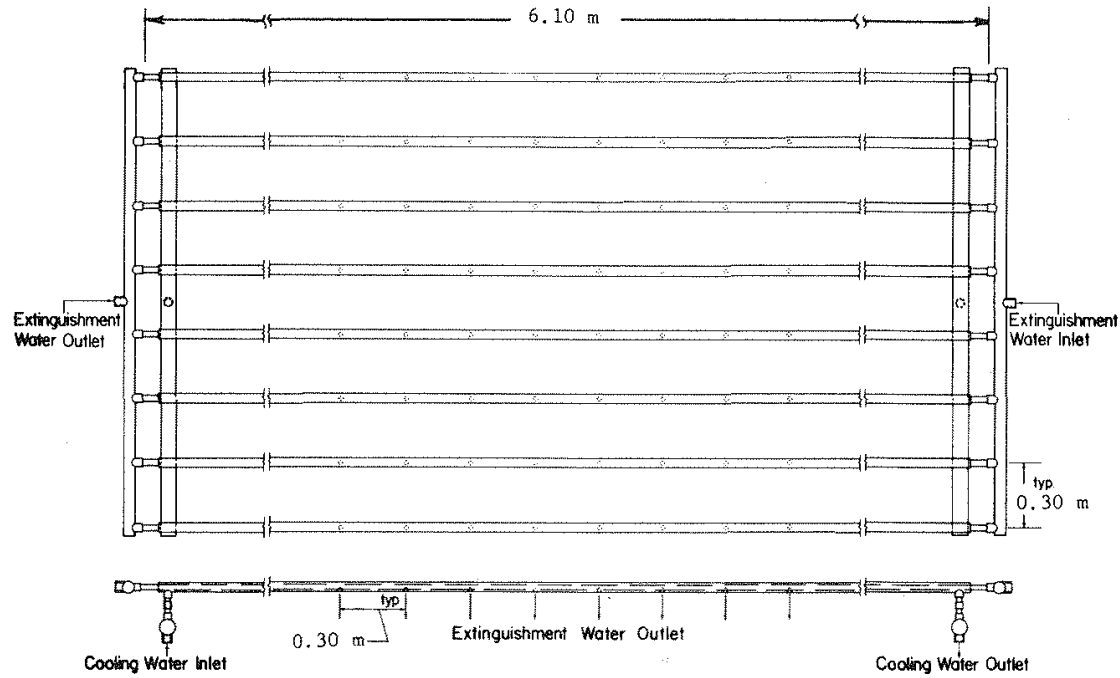

FIGURE 3. Water applicator. 
parallel steel pipes fitted with eight spray nozzles (solid cone type) along each pipe, was supported at $0.3 \mathrm{~m}$ above the top of the test array. The nozzles were spaced $0.3 \mathrm{~m}$ apart to provide a uniform coverage over the top surface of the test array which measured $2.44 \mathrm{~m} \mathrm{x} 2.44 \mathrm{~m}$. Because of the proximity of the applicator to the fuel surface, the sprays from the nozzles were assumed to have $100 \%$ penetration and the effects of drop size and spray momentum under this situation were considered to be negligible on the fire extinguishment process. The water applicator could be actuated at any point of the fire development stage to deliver a given flow rate of water directly onto the test array for extinguishment.

The entire test setup was located beneath a large-capacity calorimeter called the Fire Products Collector, which is capable of measuring fires into the megawatts range. A schematic of the collector is presented in Figure 4 and a photograph of a typical test setup in Figure 5. The Fire Products Collector was instrumented with pitot probes, thermocouples, and a gas sampling probe at the instrumentation station (located $8.7 \mathrm{~m}$ or 5.7 duct diameters from the entrance orifice above the cone) for the measurement of the total flow, temperature, and specie concentration of the gas stream in the duct. These measurements in turn allowed the heat release rates and generation rates of combustion products, such as $\mathrm{CO}_{2}, \mathrm{CO}$, and total hydrocarbons, to be calculated. Oxygen depletion rate was also included in the calculations.

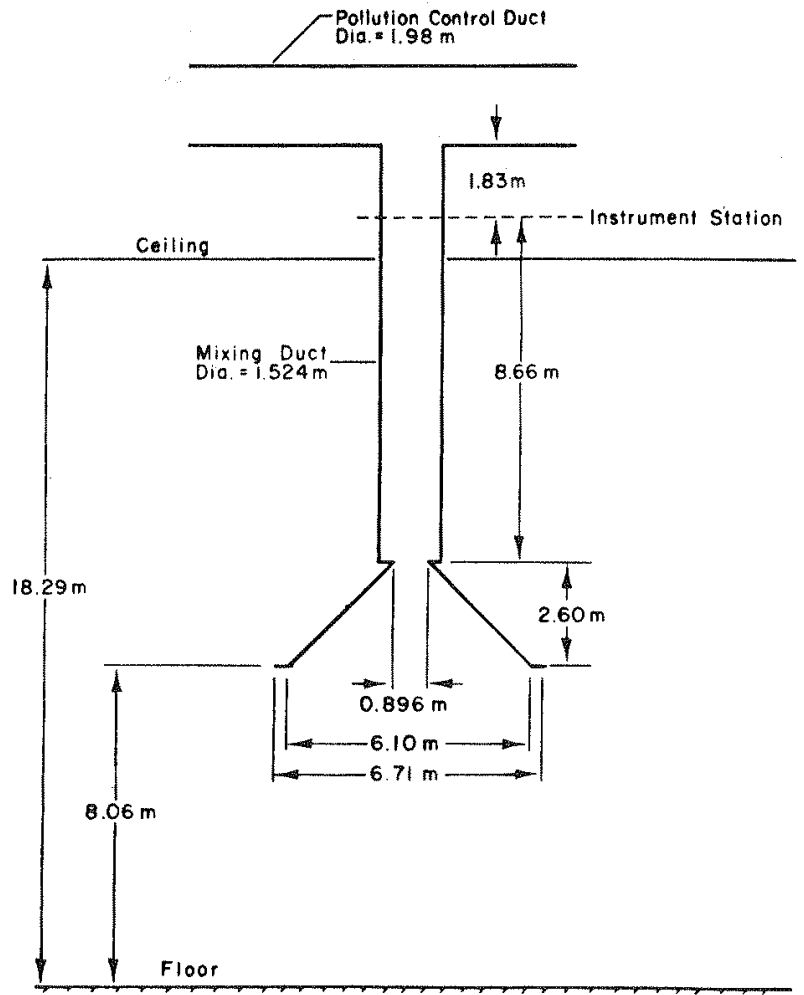

Flow Boundaries

FIGURE 4. The Fire Products Collector. 


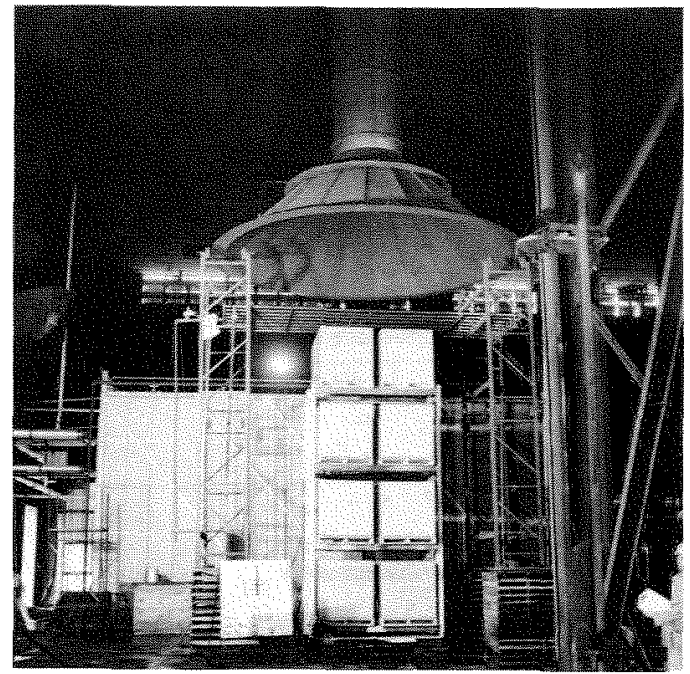

FIGURE 5. Setup for rack storage fire extinguishment test.

More details on the Fire Products Collector and the algorithms for calculating heat release rates and combustion products generation rates can be found in reference 7 .

The ignition of the test array was by means of four cellucotton rolls, $7.6-\mathrm{cm}$ dia $\times 7.6-\mathrm{cm}$ long, each soaked with $120 \mathrm{ml}$ of gasoline. Each roll was placed within a plastic bag and taped to a wooden stick. The ignitors were placed in the center flue space of the array next to the four inner corners of the lowest pallet loads. This arrangement is illustrated in Figure 6.

At the beginning of each test, before the commodities were loaded onto the rack, the water applicator was checked out and calibrated with a given water flow rate to ensure free passage through the nozzles. The commodities were then loaded and ignitors put in place. When ignition commenced, the combustion products from the fire were collected by the Fire Products Collector which continuously monitored the fire behavior of the test array. At a predetermined level of heat release rate, the water applicator was actuated, simulating the response of sprinklers in a given fire scenario, to deliver a given water application rate onto the top surface of the test array. The heat release rate from the test fire during water application was recorded and analyzed for the characterization of extinguishment behavior of the rack storage arrays.

\section{TEST RESULTS AND DISCUSSION}

The Fire Products Collector provided measurements for the calculation of convective heat release rate and total heat release rate (based on the oxygen depletion method) from the fire both before and during water application. A graph showing the convective heat release rate history measured for a given test configuration under three different water application rates is presented in Figure 7 . 


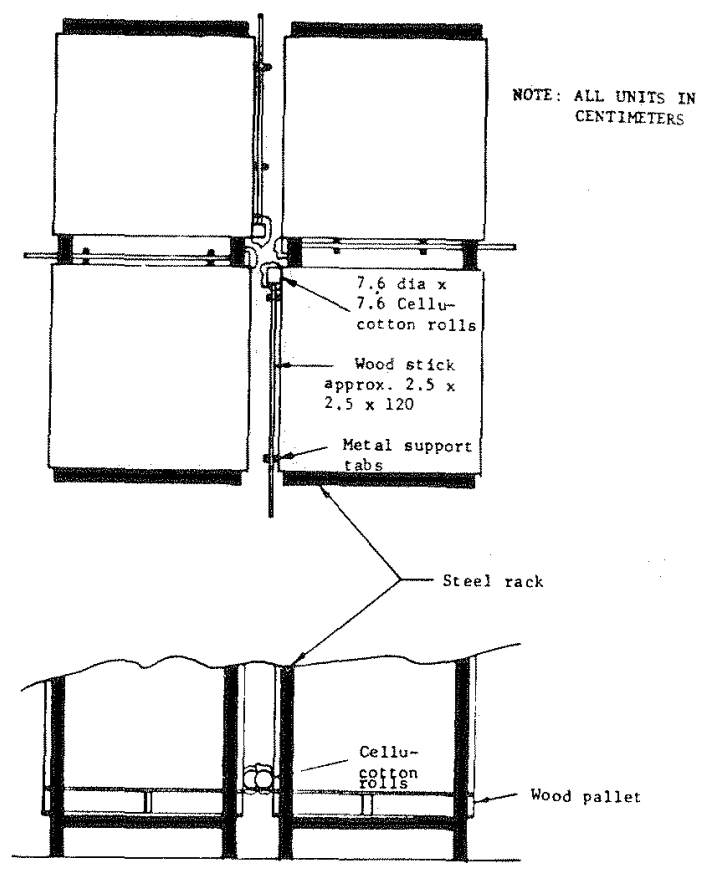

FIGURE 6. Ignition scheme.

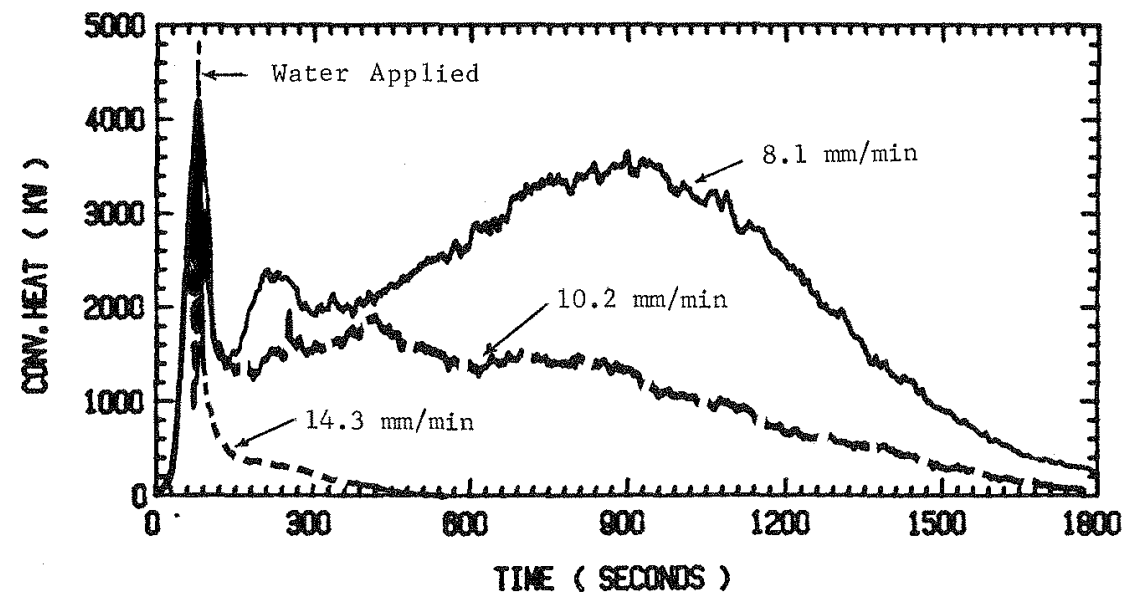

FIGURE 7. Convective heat release rate histories as a function of water application rate. 
The variables of interest in this study were the storage height of the array, the heat release rate or burning rate at water application, and the water application rate.

The parameter chosen to represent the extinguishment behavior of the test array was $E_{W}$, the total energy released from the fire during water application. $E_{W}$ is simply the integrated value of the total heat release rate of the fire from the time of water application to the end of the extinguishment process. This parameter can be converted to a more practical unit, $M_{\text {ext }}$, the mass of fuel consumed, by dividing the total energy release by the actual heat of combustion of corrugated paper. A correlation between the extinguishment results and the test variables was obtained by using a nondimensional fuel consumption parameter and a nondimensional water application rate parameter. The first parameter consisted of the ratio of mass consumed during water application to fire-consumable mass left at the moment of water application, or $M_{\text {ext }} / M_{O}, w^{*}$ The second parameter consisted of the ratio of water application rate to mass burning rate at the moment of water application, or $\dot{\mathrm{M}}_{\mathrm{W}} / \mathrm{M}_{\mathrm{b}, \mathrm{w}^{\circ}}$

Figure 8 is a plot of the nondimensional fuel consumption parameter versus the nondimensional water application rate parameter for all the extinguishment test results on rack storage fires. This correlation can be expressed as:

$$
\mathrm{M}_{\mathrm{ext}} / \mathrm{M}_{\mathrm{O}, \mathrm{w}}=0.350\left(\dot{\mathrm{M}}_{\mathrm{w}} / \dot{\mathrm{M}}_{\mathrm{b}, \mathrm{w}}\right)^{-1.55} .
$$

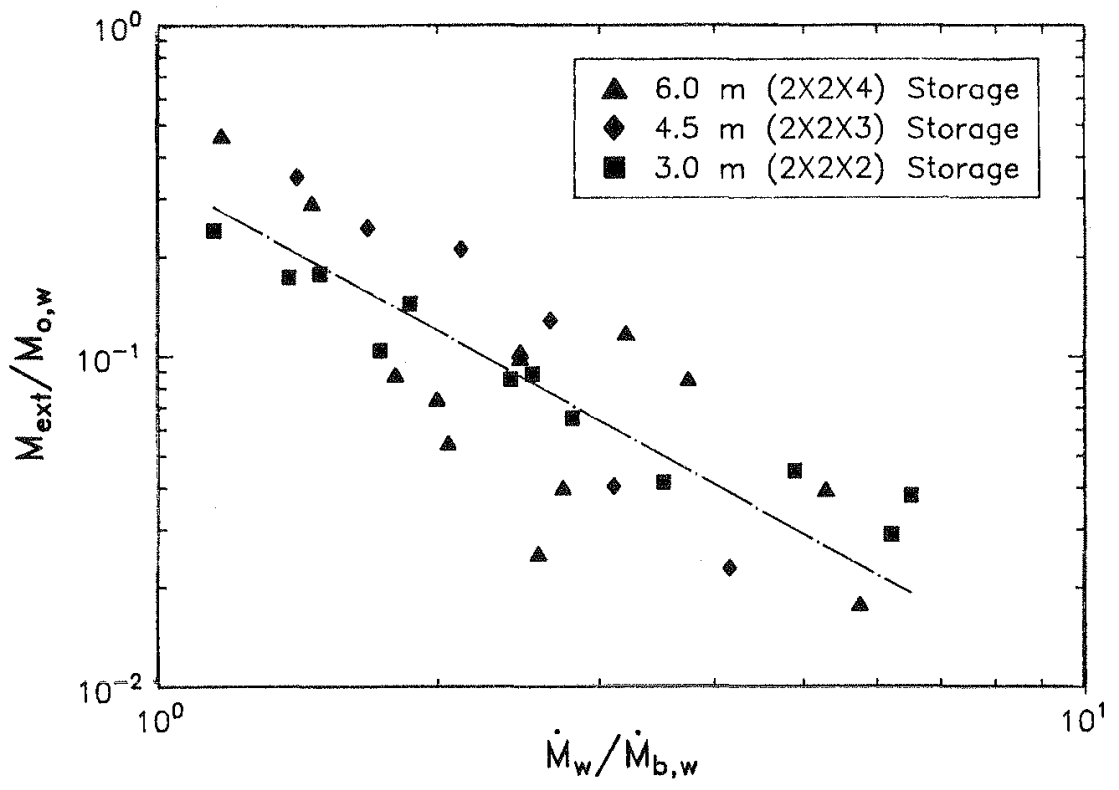

FIGURE 8. Correlation between fuel consumed during extinguishment and water application rate for rack storage array of cartons. 
In their extinction studies of wood cribs and wood pallets ${ }^{3}$, Kung and Hill also used a water application scheme similar to that used in this study to deliver different flow rates of water onto wood cribs (in three different crib heights) and wood pallets (in $1.22-\mathrm{m}$ and $2.44-\mathrm{m}$ high stacks) after different preburn periods (5-20\% of the fuel's initial weight). They correlated the extinguishment results using the same nondimensional fuel consumption parameter and the nondimensional water application rate parameter given in eq (1). However, they actually measured the mass of fuel consumed after each test instead of converting it from an energy release term. In their study, they reported a correlation of:

$$
\mathrm{M}_{\mathrm{ext}} / \mathrm{M}_{\mathrm{o}, \mathrm{w}}=0.312\left(\dot{\mathrm{M}}_{\mathrm{w}} / \dot{\mathrm{M}}_{\mathrm{b}, \mathrm{w}}\right)^{-1.55}
$$

for the wood crib tests and

$$
\mathrm{M}_{\mathrm{ext}} / \mathrm{M}_{\mathrm{o}, \mathrm{w}}=0.150\left(\dot{\mathrm{M}}_{\mathrm{w}} / \dot{\mathrm{M}}_{\mathrm{b}, \mathrm{w}}\right)^{-1.55}
$$

for the wood pallet tests. Figure 9 is a plot of the extinguishment data of the three different fuel structures with their correlations. It is interesting that, for all three fuel structures, 1) a power law relationship holds between the fuel consumption and the water application rate, and 2) a common power of -1.55 was obtained from their correlations. The primary difference is in the proportionality constants which are $0.150,0.312$ and 0.350 for wood pallets, wood cribs, and rack storage of cartons, respectively. The -1.55 power appears to be characteristic of the extinguishment process of loosely packed assemblies as suggested by Kung and Hi $11^{3}$. The variation of the proportionality constant among the three correlations implies that, for the

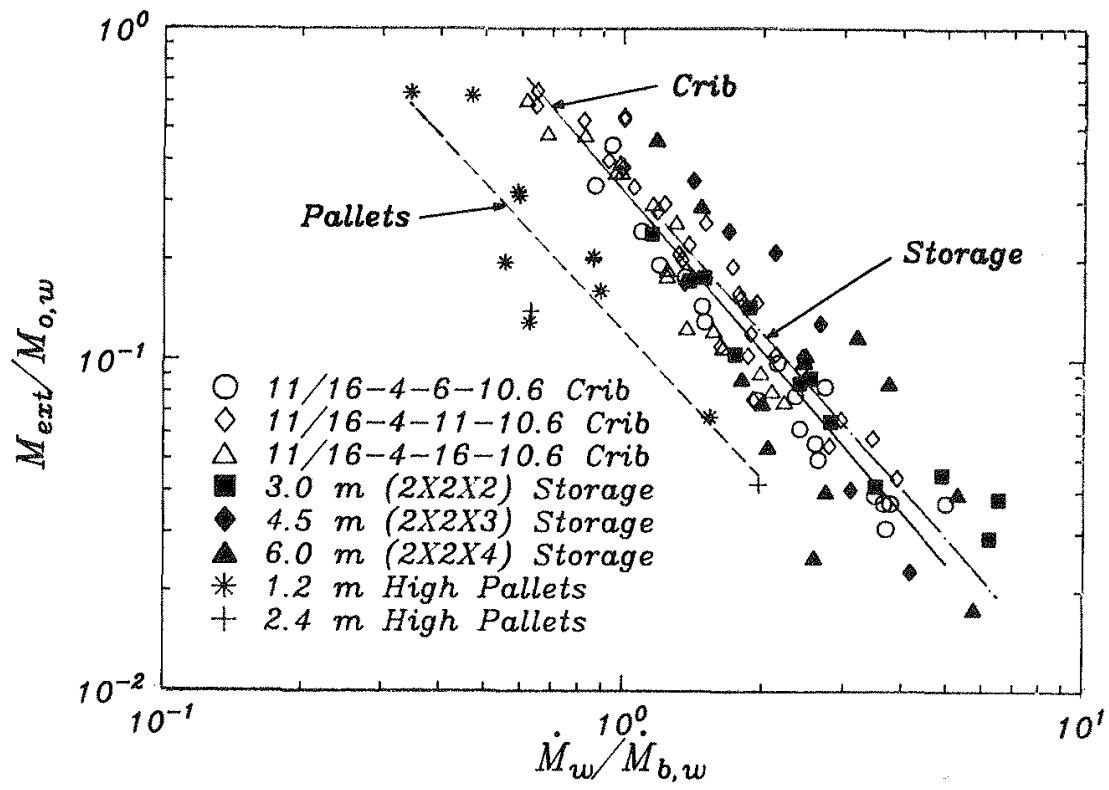

FIGURE 9. Correlations between fuel consumed during extinguishment and water application rate for wood cribs, wood pallet stacks, and rack storage array of cartons. 
same percentage of mass consumed, $\mathrm{M}_{\text {ext }} / \mathrm{M}_{\mathrm{O}}, \mathrm{W}$, the water application rate needed to suppress the rack storage fires of cartons is slightly higher than that for wood crib and even higher than that for wood pallets. This conclusion is not unreasonable in that it was much easier for the flame to penetrate through corrugated cardboard than through solid wood sticks and planks, resulting in a burning surface which is more difficult to extinguish.

Another point of interest is the critical water application rates calculated for these different fuel geometries based on their correlations. The critical water application rate is defined as the water application rate below which all burnable mass is consumed. Assuming the burning rate at water application is half the maximum burning rate of the given array, the critical water application rates per unit total exposed surface area calculated were $2.1,1.9$, and $3.0 \mathrm{~g} / \mathrm{m}^{2} \mathrm{~s}$ for wood cribs, wood pallets, and corrugated cartons, respectively. These values are very close to those reported by other researchers on wood $\mathrm{cribs}^{8}$ arranged in different configurations using different modes of water application as well as for wood $\mathrm{slab}^{8}$. This result seems to imply that the critical water application rate is not dependent on the scale and geometry of the fuel array or the mode of water application. However, it was found to be slightly dependent on the heat release rate or burning rate at the time of water application.

IV

\section{CONCLUSIONS}

In conclusion, this work shows a single correlation of the extinction data on different storage heights of rack storage arrays of corrugated cartons. A power law behavior is exhibited similar to that obtained for wood cribs and wood pallets in laboratory-scale extinction studies. Moreover, the critical water application rate obtained for cartons stored on racks is similar to those reported for wood arranged in other geometries such as crib, slab, and pallet. This finding suggests that the critical water application rate of a given material is independent of the size and geometry with which the material is arranged.

\section{REEERENCES}

1. D.J. Rasbash, "The Extinction of Fires by Water Sprays," Fire Research Abstracts and Reviews, 4, p. 28-53 (1962).

2. H. Kida, "Extinction of Fire of Sma11 Wood Crib with Sprays of Water and Some Solutions," Report of Fire Research Institute of Japan No. 36, p. 1 (1973).

3. H.C. Kung and J.P. Hil1, "Extinction of Wood Crib and Pallet Fires," Combustion and Flame, 24, p. 305, (1975).

4. F. Tamanini, "The Application of Water Sprays to the Extinguishment of Crib Fires," Combustion Science and Technology, 14, p. 17 (1976).

5. M.J. O'Dogherty and R.A. Young, "The Performance of Automatic Sprinkler Systems: Part III - The Effect of Water Application Rate and Fire Size on the Extinction of Wooden Crib Fires," Joint Fire Research Organization, Fire Research Note No. 603 (1965). 
6. M. Stolp, "The Extinction of Sma11 Wood Crib Fires by Water," 5th International Fire protection Seminar, Karlsrule, p. 127 (September 1976).

7. G. Heskestad, "A Fire Products Collector for Calorimetry into the MW Range," FMRC J.I. OC2E1.RA, Factory Mutual Research Corporation, Norwood, MA (June 1981).

8. G. Heskestad, "The Role of Water in Suppression of Fire: A Review," Journal of Fire and Flammability, 11, p. 254 (1980).

\section{NOMENCLATURE}

$\mathrm{E}_{\mathrm{W}} \quad$ total energy released from the fire during water application, $\mathrm{kJ}$

$M_{\text {ext }}$ total mass of fuel consumed during extinguishment period, $\mathrm{kg}$

$M_{o, w}$ burnable mass available at the time of water application, $\mathrm{kg}$

$\dot{\mathrm{M}}_{\mathrm{W}} \quad$ water application rate, $\mathrm{g} / \mathrm{s}$

$\dot{M}_{b, w}$ mass burning rate of the fuel at the time of water application, $g / s$ 